\title{
PARA UMA TEORIA DA INOVAÇÃO CURRICULAR
}

\author{
Roberto Rafael Dias da Silva ${ }^{1}$
}

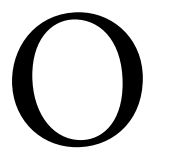

s entrelaçamentos entre inovação e mudança estão na ordem do dia no que se refere às investigações sobre a escolarização contemporânea, sobretudo no que diz respeito às questões de currículo e formação docente. Trata-se de uma temática bastante desafiadora, que é colocada no centro da obra Inovar para Mudar a Escola, escrita por José Augusto Pacheco e publicada pela Porto Editora em setembro de 2019. José Augusto Pacheco é um dos principais pesquisadores do campo dos Estudos Curriculares, especialmente no contexto luso-brasileiro, sendo atualmente professor catedrático e diretor do Instituto de Educação da Universidade do Minho, em Portugal. O autor apresenta vasta obra publicada sobre essas temáticas e, no Brasil, já publicou dezenas de artigos envolvendo questões que prioritariamente abrangem as políticas curriculares.

Neste texto, apresentaremos e comentaremos criticamente a obra supracitada, Inovar para Mudar a Escola, priorizando compor uma leitura abrangente das inúmeras proposições críticas e alternativas que se desprendem dela. Ao longo dos sete capítulos que compõem o livro, Pacheco consegue produzir uma análise ambivalente sobre a temática proposta, isto é, ao mesmo tempo que situa esse debate no âmbito do capitalismo global e das agências internacionais, consegue alargar essa compreensão para pensar uma teoria da inovação curricular, a partir de outros princípios. Esse debate adquire intensa potencialidade analítica à medida que o autor, tal como realiza em outras obras, atribui centralidade ao conhecimento.

Associa-se a essa preocupação curricular um olhar atento para a formação de professores. Ultrapassando a predominante lógica do accountability, o pesquisador português dirige sua reflexão para o fazer dos professores, na interface com as políticas e as demandas por inovação educativa. Esse posicionamento se justifica, de acordo com o autor, "porque o ensino e a aprendizagem exigem um corpus de saberes que não são reduzíveis nem à intuição pedagógica, nem ao domínio do saber da especialidade" (PACHECO, 2019, p. 8). Em termos analíticos, merece destaque o referencial teórico bastante abrangente que perfaz a composição do estudo, seja ao multiplicar olhares sobre a mudança educativa, seja ao construir uma leitura crítica das políticas educativas e curriculares em implementação. Considerando a natureza conceitual da obra que será examinada, a partir deste momento realizaremos uma apreciação de cada um dos sete capítulos que a estruturam.

O primeiro capítulo intitula-se "Transglobalidade: uniformidades e multiplicidades" e destina-se a uma contextualização das questões sociais emergentes neste início de século. Por meio do conceito de "transglobalidade", Pacheco examina a globalização e as relações econômicas hodiernas,

Resenha do Livro: Inovar para mudar a escola, de José Augusto Pacheco.

O presente estudo deriva-se do projeto de pesquisa "Estetização Pedagógica, Aprendizagens Ativas e Práticas Curriculares: Um Estudo Acerca da Individualização dos Percursos Formativos no Ensino Médio”, financiado pelo CNPq.

1.Universidade do Vale do Rio dos Sinos - Escola de Humanidades - Programa de Pós-graduação em Educação - São Leopoldo (RS), Brasil. E-mail: robertods@unisinos.br

Editor de Seção: Lícinio C. Lima 
evitando reduzi-las a processos de estandardização e homogeneização. Reconhece que um texto sobre inovação precisa dimensioná-la em um quadro conceitual mais abrangente e, no caso da escola, faz-se urgente distanciar-se de modelos que visam referenciar a educação "como produção eficaz e eficiente do conhecimento e competências exigidos pela sociedade baseada na economia do conhecimento, que tem sido dominante nas últimas décadas" (PACHECO, 2019, p. 16). Em tais condições, o conceito de transglobalidade evidenciou potencial heurístico para compor um diagnóstico em que a pluralidade da globalização ocorre em ritmos múltiplos e variáveis, ampliando seus sentidos hoje predominantes.

Tal como no capítulo anterior, em "Movimentos de reforma da escola", o pesquisador português segue produzindo uma elaboração crítica sobre a escolarização ocidental. Foca, nesse segundo capítulo, nas mudanças curriculares propostas pelos reformadores no decorrer do século passado, sinalizando a transição de um movimento em defesa da escola comum até chegar a uma tendência atual em produzir padrões de desempenho. Inspirado nos estudos de David Labaree (2012), defende que "o sistema escolar não tem sido bem-sucedido na sua missão social” (PACHECO, 2019, p. 22), uma vez que, mesmo mudando continuamente, as escolas preservam muito daquilo que já faziam a nomeada "síndrome da escola". Em outras palavras, muda-se para continuar como sempre se foi ou são realizados acréscimos - como o retorno à racionalidade tyleriana, por exemplo - ineficazes no enfrentamento das desigualdades e na promoção de oportunidades.

No que tange à formação de professores, foco reflexivo do terceiro capítulo, "Formação de Professores", Pacheco amplia seu diagnóstico para pensar os saberes profissionais e a aprendizagem profissional docente nesse contexto em que se hegemonizam os sistemas de accountability. O privilégio dessa racionalidade técnica traz significativas implicações para o currículo e para os modos de selecionar e organizar o conhecimento na escola. Constata-se uma convergência entre os currículos padronizados e os modelos de formação docente defendidos por determinadas agências globais, o que Pacheco busca contrapor por meio de uma retomada do conceito de "aprendizagem profissional docente".

Em “Trabalho docente em contexto de accountability”, quarto capítulo, o pesquisador segue alargando sua abordagem crítica sobre a escolarização contemporânea e, nesse tempo, dirige-se ao perfil docente em uma escola voltada para resultados. Argumenta que, no hodierno modelo global de governança, as culturas escolares são regidas pelas lógicas da prestação de contas e dos resultados, o que tem implicado fortes mudanças na concepção de trabalho docente e aprendizagem. Em suas palavras, “impera, assim, no interior das escolas, uma abordagem curricular centrada nos resultados, fazendo crer que os resultados são o principal motor das reformas a empreender e que o professor apenas precisa de ser formado no domínio dos conteúdos a ensinar e nas técnicas de ensinar" (PACHECO, 2019, p. 49). O trabalho docente, sob a perspectiva desta forma de governamentalidade curricular, percebe a aprendizagem de modo utilitário, promovendo uma escolarização restrita.

No quinto capítulo, intitulado "Conhecimento e aprendizagem: entre números e pessoas", Pacheco encerra a parte do livro dedicada à crítica política apreciando as articulações entre Estado, mercado e sujeito. Ao retomar as finalidades sociais da escola moderna e a emergência da educação obrigatória, o autor sinaliza os modos pelos quais o Estado Moderno cumpriu uma tarefa civilizatória e impulsionadora das identidades sociais. Outrossim, ao articular-se com as prerrogativas do mercado e da globalização, assistimos ao advento e à consolidação das estatísticas educacionais, ora mapeando a abrangência do ensino, ora indicando as metas e expectativas avaliativas. Ao longo do século XX, de modo biopolítico, o Estado regulou seus investimentos educativos por meio de um governo pelos números. Isto é, as clássicas dimensões curriculares do conhecimento e da aprendizagem foram dimensionadas, de modo eficientista, em escalas de desempenho. 
Nesses primeiros cinco capítulos da obra, José Augusto Pacheco tratou de construir um diagnóstico crítico - preciso e perspicaz - dos modos pelos quais a escolarização contemporânea tem sido regulada. Nos capítulos finais, que revisaremos a partir de agora, propõe-se outro exercício intelectual, qual seja: a construção de referenciais para uma teoria da inovação curricular. Sua abordagem sugere que possamos repensar a inovação como uma estratégia de mudança da escola, articulada com as dimensões do currículo, da formação docente e das políticas educativas. Os próximos dois capítulos, então, assumem uma perspectiva propositiva.

Em “Desafios contemporâneos aos professores", sexto capítulo, o pesquisador português constrói uma abordagem sobre o conhecimento, as aprendizagens, a profissionalidade docente, a atitude cosmopolita, o envolvimento parental, a equidade, a inovação e as emoções. A partir de um prisma heterodoxo, Pacheco cartografa desafios atrelados a cada um dos oito conceitos mencionados. Merecem destaque suas articulações entre democracia e justiça social, coadunadas ao par conhecimentomobilidade social. Cada um desses desafios é bastante pertinente; entretanto, gostaríamos de enaltecer aquele vinculado à inovação - eixo estruturante da proposta analítica da obra.

Ao fim, no capítulo intitulado "Para uma teoria da inovação curricular", são apresentados elementos teóricos que poderiam referenciar a busca pela inovação no currículo. Ao diferenciar expressões aparentemente similares, como inovação, mudança e reforma, em diálogo com Lessard e Carpentier (2016), são explicitadas três questões essenciais para a compreensão da inovação: "Que referenciais da educação estão em jogo? Que teorias da mudança são valorizadas? Que tecnologias de mudança são focadas?” (PACHECO, 2019, p. 90). Em busca por referenciais para uma agenda de inovação, Pacheco se remete a pensá-la como "elo dinâmico da mudança", "projeto" e "acontecimento". Trata-se de uma trama conceitual bastante potencializadora de reflexões, uma vez que assume a inovação a partir de referenciais educativos, distanciando-se da retórica empresarial que assombra essa construção conceitual. Em suas palavras, "a inovação pode ser uma estratégia virada para o futuro" (PACHECO, 2019, p. 142), à medida que pode estar sintonizada com as questões curriculares, políticas e de formação dos docentes.

Importante ainda destacar que a teoria da novação curricular, esboçada nessa obra, cumpre um papel político importante, uma vez que se afasta dos modelos de inovação que operam na exclusiva busca de resultados, de aparatos técnicos ou por mero modismo. Em sua teoria, a gramática da democracia e da responsabilidade compartilhada pelo futuro adquirem centralidade, substituindo a responsabilização que era predominante. Cabe às comunidades escolares a promoção de novas formas de pensar e agir, no sentido das escolas criativas defendidas por Ken Robinson e Lou Aronica (2019).

Assim sendo, ao percorrermos os sete capítulos que constituem esta obra, conseguimos constatar seu potencial crítico e propositivo para pensar a escolarização contemporânea. José Augusto Pacheco, com muita sensibilidade intelectual, consegue estabelecer os traços conceituais para uma teoria da inovação curricular. Sua tarefa foi bastante ousada, na medida em que os territórios da inovação são controversos e permeados por disputas simbólicas nos âmbitos da economia e da cultura. Inovar para Mudar a Escola, em nossa perspectiva, é leitura obrigatória para aqueles que desejam compreender e projetar uma escola democrática e inovadora no século XXI.

\section{Referências}

LABAREE, D. School syndrome: understanding the USA's magical belief that schooling can somehow improve society, promote access, and preserve advantage. Journal of Curriculum Studies, London, v. 44, n. 2, p. 143 163, 2012. https://doi.org/10.1080/00220272.2012.675358 
LESSARD, C.; CARPENTIER, A. Políticas educativas: a aplicação na prática. Petrópolis: Vozes, 2016.

PACHECO, J. A. Inovar para mudar a escola. Porto: Porto Editora, 2019.

ROBINSON, K.; ARONICA, L. Escolas criativas. Porto Alegre: Penso, 2019.

\section{Sobre o Autor}

Roberto Rafael Dias da Silva é mestre (2008) e doutor (2011) em Educação pela Universidade do Vale do Rio dos Sinos (UNISINOS). É Licenciado em Pedagogia pela Universidade Estadual do Rio Grande do Sul (UFRGS), em 2005, e Professor do Programa de Pós-graduação em Educação da UNISINOS, onde atua na linha de pesquisa Formação de Professores, Currículo e Práticas Pedagógicas.

Recebido: 4 maio 2020

Aprovado: 21 ago. 2020 